\title{
(3) \\ Endoscopy management algorithms: role of cyanoacrylate glue injection and self-expanding metal stents in acute variceal haemorrhage
}

\author{
G El Sayed, ${ }^{1}$ S Tarff, ${ }^{1}$ J O'Beirne, ${ }^{2}$ G Wright ${ }^{1,2}$
}

\begin{abstract}
${ }^{1}$ Department of
Gastroenterology, Basildon \& Thurock University Hospital, London, UK

${ }^{2}$ Sheila Sherlock Liver Centre, Royal Free Hospital, London, UK
\end{abstract}

\section{Correspondence to}

Dr G El Sayed, Department of Gastroenterology, Basildon \& Thurrock University Hospitals, London, SS16 5NL, UK; ghassanovii@yahoo.co.uk

Received 19 December 2013 Revised 24 May 2014 Accepted 26 May 2014 Published Online First 23 June 2014

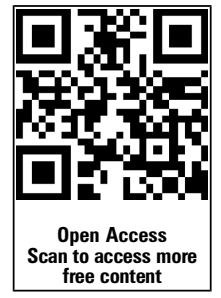

CrossMark

To cite: El Sayed G, Tarff S, O'Beirne J, et al. Frontline Gastroenterology 2015:6:208-216.

\begin{abstract}
Mortality from acute variceal bleeding (AVB) has improved markedly over the last 2-3 decades due to increased specialisation and

standardisation of medical and endoscopic practice culminating in the production of consensus guidance based on expert opinion. Nonetheless, despite greater exposure, training and endoscopic practices, 30-day mortality still remains high at around $30 \%$. This is a reflection of the high morbidity with liver disease, and limited endoscopic experience and/or endoscopic techniques used by the majority of general endoscopists. Clinical necessity defines our drive for further endoscopic innovation to improve 'best practice' and, therefore, clinical outcomes accordingly. Sclerotherpy, variceal band ligation and/or rescue balloon tamponade have been entrenched in most treatment algorithms over the decades. However, in recent years and albeit limited to specialised liver centres, cyanoacrylate glue injection therapy (for oesophageal and gastric varices), and the placement of a selfexpanding metallic stent for oesophageal varices have begun to offer improved endoscopic care in experienced hands. Yet even in specialised centres, their application is sporadic and operator dependent. Here, we discuss the evidence of these newer endoscopic approaches, and hope to propose their inclusion in endoscopic therapy algorithms for 'best practice' management of AVB in all appropriately supported endoscopy units.
\end{abstract}

\section{BACKGROUND}

Around $30-60 \%$ of patients with cirrhosisrelated portal hypertension (PHT) develop varices as a physiological compensatory mechanism to limit portal venous pressure. Of the $10 \%$ of cirrhotics who develop varices each year, $10 \%$ per year actually bleed. Collectively, acute variceal bleeding (AVB), 'bleeding in the presence of varices without another identifiable cause', occurs in around 30\%, ${ }^{1}$ and accounts for 70 $80 \%{ }^{2}$ of all upper gastrointestinal bleeding episodes in patients with PHT. Due to improved medical, endoscopic and interventional management, mortality from AVB has fallen from 50\% to around 30\% over the past 30 years, but this is still high, and the abolition of AVB remains a clear therapeutic goal.

The mainstay of therapy for AVB in centres with the necessary facilities involves fluid resuscitation, prophylactic antibiotics, ${ }^{3}$ and vasoactive drugs (eg, Terlipressin) combined with endoscopic intervention. Traditional sclerosants such as ethanolamine have been superseded due to high variation in successful AVB arrest (26-100\%) and rebleeding rates (60-90\%) due to differential endoscopic skill (eg, sclerosant volume injected) and $25 \%$ complication rate. ${ }^{4}$ Nowadays, variceal band ligation (VBL) has become the mainstay of endoscopic therapy (grade 1A evidence) and the backbone of UK guidance on the endoscopic management of variceal bleeding. ${ }^{5}$ In patients with Childs-Pugh score (CPS) A or B cirrhosis such measures correlate with a $90 \%$ 30-day survival, but equally, therefore, $10 \%$ of CPS A-B patients still die despite intervention. This figure is inherently higher in those patients with poor end-organ reserve (CPS C) especially where there has been a failure to gain primary bleeding arrest and/or they rebleed; such that further supportive and endoscopic intervention becomes increasingly challenging. 
As a means of bridging the patient to either more definitive therapy, rescue therapies like balloon tamponade (BT) may be necessary, though frequently performed in acutely unstable circumstances by those with limited experience, resulting in greater potential for complication. A failure of primary AVB arrest, rebleeding and/or complications from prior intervention (eg, VBL, BT etc.) not uncommonly requires repeat endoscopic intervention by an experienced endoscopist, and/or insertion of a transjugular intrahepatic portosystemic shunt (TIPS). Aside from BT, most of these therapies are not universally available, and are chiefly limited to larger specialised centres and/or in some circumstances contraindicated if not considered futile by many non-specialists given the traditionally pessimistic approach of non-specialists to patients with chronic liver disease.

Regardless, endoscopic therapy remains central to the management of oesophageal and gastric AVB, but different anatomical considerations dictate a varied response to interventions for oesophageal and gastric varices. Recently, in primarily specialist centres, two new endoscopic modalities have become increasingly prominent in AVB management, (1) cyanoacrylate
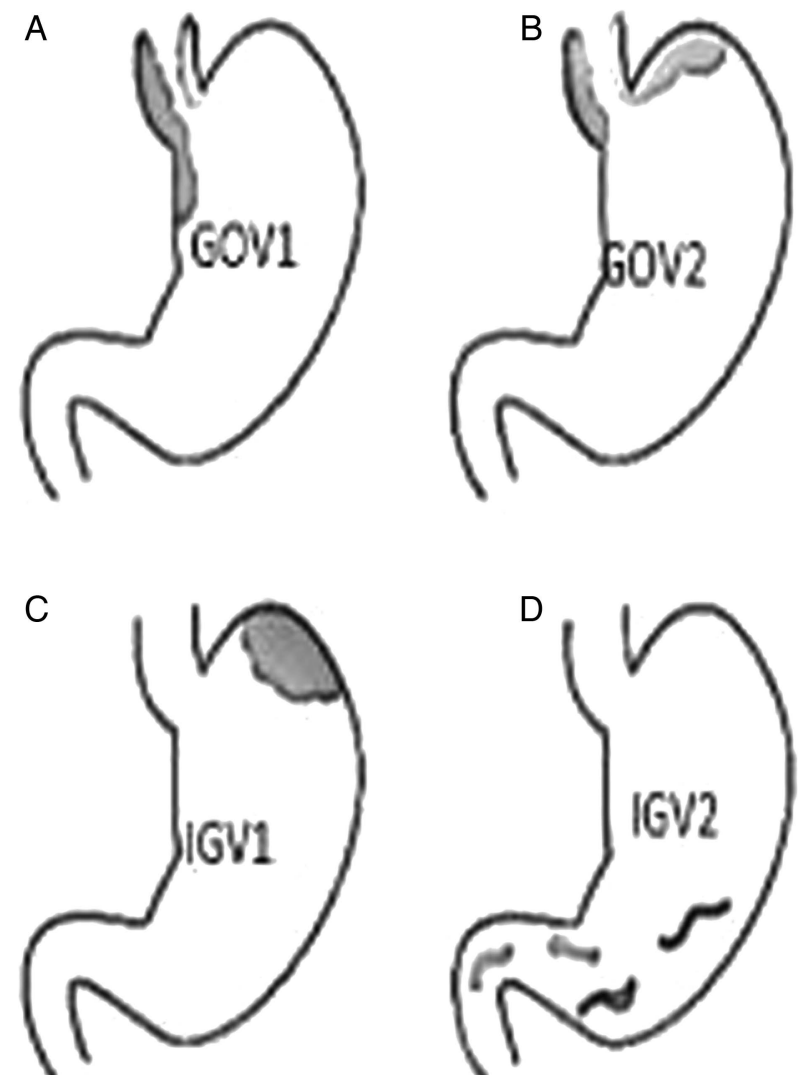

Figure 1 (A-D): Gastric variceal anatomy. Classification of different types of gastric varices based on their anatomical position in the stomach are depicted in figure (A). GEV1: gastro-oesophageal varices type 1, (B). GEV2: gastro-oesophageal varices type 2, (C). IGV1: isolated gastric varices type

1. (D) IGV2: isolated gastric varices type 2 . (glue) injection therapy and (2) self-expandable metal stent (SEMS). This review focuses on these two therapies and proposes their wider inclusion in guidance on endoscopic variceal management within endoscopy units including non-specialist centres which have appropriate expertise and support.

\section{VARICEAL ANATOMY}

To best understand differing therapeutic endoscopic considerations for the management of AVB, one must understand the anatomical differences in variceal formation, as although gastric varices bleed less frequently, they are often associated with a more severe bleed that may be more difficult to manage.

\section{Oesophageal varices}

Oesophageal varices normally result from PHT as a complication of cirrhosis, or prehepatic or posthepatic vascular occlusion. Actually, the majority of blood from the oesophagus is not involved in variceal formation as the oesophageal veins drain into the azygos vein and then the superior vena cava. However, the remaining blood drains from the oesophagus via the superficial veins lining the oesophageal mucosa, which then flows into the left gastric vein (coronary vein) and, in turn, drains directly into the portal vein. With progressive PHT these superficial veins (normally only $\sim 1 \mathrm{~mm}$ in diameter) become distended to form varices $(\sim 1-2 \mathrm{~cm}$ in diameter). In health only a small amount of blood flows from the oesophagus into the left gastric vein; these are the channels that enlarge in portal hypertension (HTN) and blood flow is reversed.

Normal portal pressure is approximately $9 \mathrm{~mm} \mathrm{Hg}$ compared to an inferior vena cava pressure of 2-6 $\mathrm{mm} \mathrm{Hg}$, creating a pressure gradient of 3-7 mm Hg. If the portal pressure rises above $12 \mathrm{~mm} \mathrm{Hg}$, this gradient rises to $7-10 \mathrm{~mm} \mathrm{Hg}$. A gradient $\geq 5 \mathrm{~mm} \mathrm{Hg}$ is considered PHT and at gradients $\geq 10 \mathrm{~mm} \mathrm{Hg}$, hepatic portal blood is redirected from the liver to form collateral circulation at areas with lower venous pressures (eg, oesophagus, abdominal wall, stomach and rectum). As pressures rise, these collateral vessels become increasingly distended and thin-walled, appearing as varicosities that may easily bleed, as also poorly supported by surrounding structures.

\section{Gastric varices}

Gastroesophageal varices are an extension of oesophageal varices and are categorised (figure 1) by their relationship to oesophageal varices and location in the stomach. Type-1 (GOV1) varices extend along the lesser curvature and are considered extensions of oesophageal varices and therefore similarly managed. Type-2 (GOV2) gastric varices extend along the fundus and tend to be longer and more tortuous. Isolated gastric varices (IGV) occur in the absence of 
oesophageal varices and are also classified into two types (figure 1). Type 1 (IGV1) are located in the fundus and tend to be tortuous and complex, and type 2 (IVG2) are located in the body, antrum or pylorus. The presence of isolated IGV1 fundal varices requires that one excludes the presence of splenic vein thrombosis which is often the trigger of IGV.

\section{ENDOSCOPIC MANAGEMENT}

Traditionally, oesophageal varices are treated with VBL and/or sclerotherapy. VBL has proven more beneficial especially versus the traditional (and now outdated) sclerosant agents such as alcohol and ethanolamine. ${ }^{6}$ However, newer agents like 'cyanoacrylate' glue injection therapy have quickly shown benefit in the management of oesophageal and gastric varices

\section{ENDOSCOPIC MANAGEMENT OF OESOPHAGEAL VARICES}

To date, there has been limited data assessing the role of glue therapy in the treatment of oesophageal variceal bleeding (OVB). The largest series and most convincing evidence comes from a prospective study of 133 consecutive cirrhotic AVB patients treated by intravariceal glue injection. ${ }^{7}$ Immediate haemostasis was achieved in $94.2 \%(n=49 / 52)$ of those with active bleeding. Early recurrent bleeding occurred in 5.2\% $(n=7 / 49)$ with no major procedure-related complications reported, but overall bleeding-related mortality was $8.2 \%$ and, not unsurprisingly, higher $(15.4 \%)$ in those with active bleeding at endoscopy compared to $(3.7 \%)$ non-active bleeders. However, of those surviving the first bleeding episode, $84 \%(n=112 / 133)$ subsequently underwent oesophageal band ligation (OBL). Therefore, one can only conclude that although not first-line, emergency glue injection is generally safe and effective for the treatment of acute OVB and does not hinder subsequent OBL. However, this study did not mention the degree of liver cirrhosis and other organ dysfunction which would generally predict poor outcomes in those patients.

\section{ENDOSCOPIC MANAGEMENT OF GASTRIC VARICES}

Gastric variceal bleeding (GVB) accounts for 10-15\% of all variceal bleeds (figure 4). Following general supportive measures (eg, resuscitation, terlipressin and antibiotics), the endoscopic management of acute GVB is difficult in the light of active bleeding or rebleeding as often technically challenging given gastric variceal anatomical and physiological considerations. Although successful haemostasis and obliteration of gastric varices are reported with VBL and certain sclerosing agents (eg, absolute alcohol), results are variable if not typically poor. ${ }^{8}$ Where primary haemostasis was not achieved and/or later re-bled, BT is necessary to bridge the patient to more definitive intervention such as TIPS, surgical shunt and, if appropriate, transplantation. If locally available, and in appropriate patients (eg, absence of significant HE episode) early TIPS placement is known to arrest AVB and reduce rebleeding rates from oesophageal and gastric varices, ${ }^{9}$ by reducing portal pressure as AVB is unlikely if hepatic vein pressure gradient (HVPG) is $\leq 12 \mathrm{~mm} \mathrm{Hg},{ }^{10}$ Even with successful TIPS (reducing HVPG $\leq 12 \mathrm{~mm} \mathrm{Hg}$ ), gastric varices have a tendency to bleed despite low portal pressures. However, over recent years, there has been the increasing and successful application of cyanoacrylate glue therapy for refractory oesophageal and gastric AVB leading to immediate haemostasis and variceal obliteration. Based on published evidence, glue is more effective than band ligation for gastric varices.

\section{CYANOACRYLATE INJECTION THERAPY}

\section{Administration}

The tissue glue, N-butyl-2-cyanoacrylate, is a watery solution that polymerises and hardens within $20 \mathrm{~s}$ in a physiological milieu and instantaneously on contact with blood. Rapid solidification of glue makes endoscopic application technically difficult, necessitating its dilution with the oily contrast agent Lipiodol Ultra Fluid (Therapex, Canada) to improve administration (figure 2). A 50:50 mixture of cyanoacrylate and Lipiodol (in preference to saline) is arguably the best dilution protocol for injection as allows for controlled application and limited risk of embolisation. A therapeutic endoscope with a $3.7 \mathrm{~mm}$ working channel is preferred to allow for accurate control of the injector catheter (a standard gastroscope with a $3.2 \mathrm{~mm}$ channel often does not allow the injection catheter to pass when the gastroscope is retroflexed in the stomach). There had been no consensus to whether glue therapy should be in the treatment algorithm for either oesophageal or gastric AVB, and what recent studies have been reported are relatively small, nonrandomised and have not been compared with endoscopic variceal ligation (EVL), the current standard of care. $^{11}$

\section{Evidence for cyanoacrylate in GVB}

There has been a number of small non-randomised studies, mainly case series, of GVB treated with cyanoacrylate glue therapy. Collectively, in over 1000 reported cases, active variceal bleeding was arrested in 93-100\%, with rates of recurrent bleeding around $10 \%$.

In a case series of $34 \quad(n=34)$ patients receiving primary glue therapy for AVB, $93.8 \%$ achieved immediate haemostasis with variceal obliteration in $84 \%$. Only $11.8 \%(n=4)$ re-bled within $48 \mathrm{~h}$, and a superior mesenteric vein thrombosis complicated one case. There was a treatment failure-related mortality of only $2.1 \%(n=1)$, with $82.4 \%(n=28)$ of patients alive at the end of follow-up. 


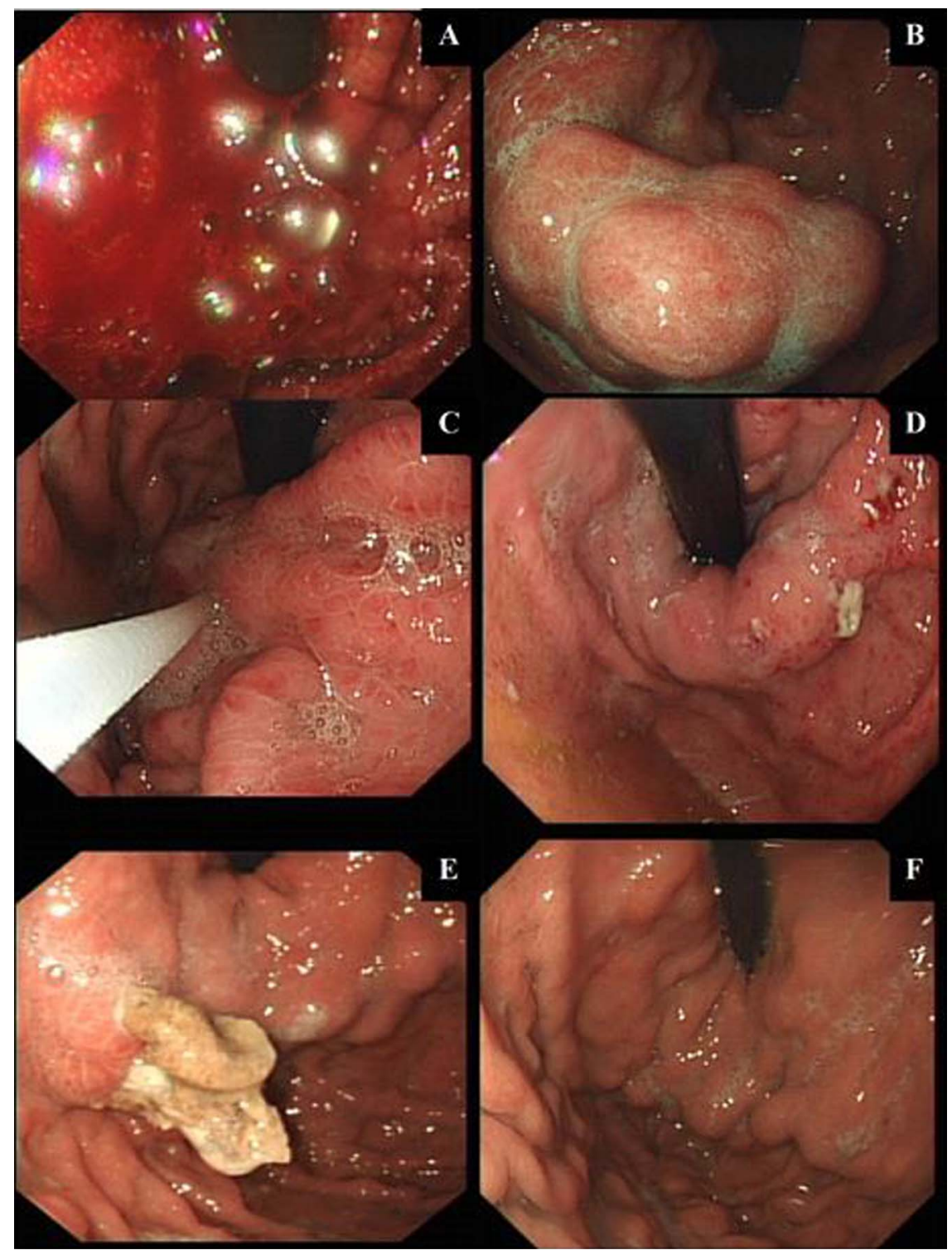

Figure 2 (A-F): Temporal endoscopic views of glue-injection therapy for an acute VGB and subsequent treatment response. Endoscopic images from serial endoscopies (over 4 weeks) for a patient treated with intravariceal glue-injection therapy for a massive acute variceal bleeding (AVB) are represented in (A). Gastroscopy within $24 \mathrm{~h}$ of presentation (when patient stabilised following standard medical care and necessary resuscitation) showing an ongoing active bleeding from a GOV1 gastric varix. A

Sengstaken-Blakemore tube (BT) was inserted immediately, as the endoscopist had little experience with glue therapy. (B) Appearance of gastric varices $8 \mathrm{~h}$ post-BT and prokinetic to aid endoscopic views. (C) Injecting varices with glue (histoacryl and lipiodol-mixed solution). (D) Early extravasation of glue (histoacryl and lipiodol solution) 48-72 h post-glue injection therapy. (E) Well formed histoacryl and lipiodol cast, 2 weeks postinjecting therapy. (F) Complete eradication of gastric varices with histoacryl and lipiodol therapy.

Similarly, Jaber Al-Ali et al ${ }^{12}$ reported $95 \%$ primary haemostasis with cyanoacrylate glue injection in 37 $(n=37)$ cases of GVB. Early or late rebleeding occurred in only $8 \%(n=3)$ and $28 \%(n=10)$, respectively, and all 'non-life-threatening'. Over 14 months follow-up (achieved in 79\%), all-cause mortality rate was $28.6 \%(n=11)$, with no significant cyanoacrylate injection-related complications.

Rajoriya et al,,$^{13}$ reported $100 \%$ primary haemostasis with cyanoacrylate glue injection in $31 \quad(n=31)$ GVB patients with more advanced disease (CPS B/C) and active bleeding (58\% periprocedure). Over the 35 -month mean follow-up (57 months for survivors), rebleeding rate was $10 \%$ at 1 year and $16 \%$ in total. Thirteen per cent required subsequent TIPS, with 1 and 2 -year mortality of $23 \%$ and $35 \%$, respectively.

\section{Complications with cyanoacrylate administration}

Endoscopic glue-injection therapy is not without risk as is associated with distal systemic thromboembolic events, such as pulmonary embolism (pulmonary vessels), acute kidney injury, ${ }^{14}$ (renal vessels) as well as 
obliteration of splenic or portal vein; the latter potentially precluding liver transplantation. There have been other reported complications, such as gastric ulcer formation $(0.1 \%)$, major GVB $(0.1 \%)$, and mesenteric haematoma, haemoperitoneum, bacterial peritonitis $(0.1 \%)$, and reports of recurrent and prolonged bacterial sepsis due to retained embolised glue casts. ${ }^{14}$ Retained material may act as an infective foci ${ }^{14}{ }^{15}$; with subsequent cast breakdown intermittently releasing colonised microbes into the circulation. Therefore, embolised glue may persist beyond 24 weeks and should be considered if recurrent infection develops, which may necessitate protracted courses of antibiotics. This reiterates the need for caution with glue. To potentially reduce such risks endosonographic-endoscopic ultrasound (EUS) or fluoroscopic-guided administration is advocated in certain countries, but as yet is not general practice in the UK. Direct ultrasound-guided endoscopy should offer safer gastric variceal puncture, partly due to a more stable position in the lower oesophagus in comparison with gastric retroflexion. Such targeted intervention should reduce glue volume, especially with synthetic fibre coil placement, and reduce the risk of systemic complications (eg, PE). EUS also allows for surveillance to predict the risk of further bleed.

\section{ENDOSCOPIC ULTRASOUND-GUIDED THERAPY (EUS)}

EUS began in 1980 and over the years has become an integral part of diagnostic and interventional endoscopy. EUS-guided therapy offers a potentially safer approach to the management of GVB given reports of glue embolisation and potential fatality complicating endoscopic glue therapy. EUS-guided therapeutic endoscopy is considered by some experts to allow for more targeted glue and/or coil deployment in bleeding or non-bleeding gatric fundal varix (GFV) and aid variceal obliteration. ${ }^{16}$ In 2013, Romero-Castro et al published a series of 30 consecutive patients with IGV who received either EUS-guided glue injection $(n=11 /$ $30)$ or endoscopic coil application (ECA) $(n=19 / 30)$ with up to 6 months postprocedure review. ${ }^{17}$ The GV obliteration rate with EUS-guided glue injection was $94.7 \%$ vs $90.9 \%$ for EUS-guided ECA, with adverse events occurring in $40 \%$ (57.9\% of glued patients, but only $9.1 \%$ post-ECA $(\mathrm{p}<0.01))$. Interestingly, $81 \%$ of those glued showed CT evidence of embolism (sites not reported) though $80 \%$ of these were asymptomatic. Although 20\% $(n=6 / 30)$ of study patients died over the study follow-up period, all were unrelated to endoscopy or AVB. ${ }^{17}$ EUS-guided glue injection and ECA, therefore, showed excellent and comparable clinical benefit though it could be argued that ECA may be the safer modality. In AVB patients, Binmoeller $e t \mathrm{al}^{16}$ had previously assessed if combining ECA (incorporating attached synthetic fibres) to EUS-guided glue injection would reduce the risk of glue embolisation (presumably by limiting total injected glue volume). Patients with acute $(\mathrm{n}=2)$ or recent stigmata $(n=14)$ of GVB were studied and followed-up over a 2-year period. Haemostasis was achieved in $100 \%$, with variceal obliteration observed after a single treatment session in $96 \%$. In the $16 \%$ of those who re-bled, none was due to GVB. Importantly, there were no endoscopy-related complications or evidence of glue embolisation.

\section{SEMS FOR OVB}

Placement of a fully covered SEMS is a promising therapeutic technique to control cases of refractory oesophageal bleeding as an alternative to BT (figure 3). SEMS further allow for an immediate return to enteral feeding and can be left in place for 1-2 weeks to allow for improvement in liver function and a bridge to the institution of more definitive treatment (eg, TIPS or transplantation).

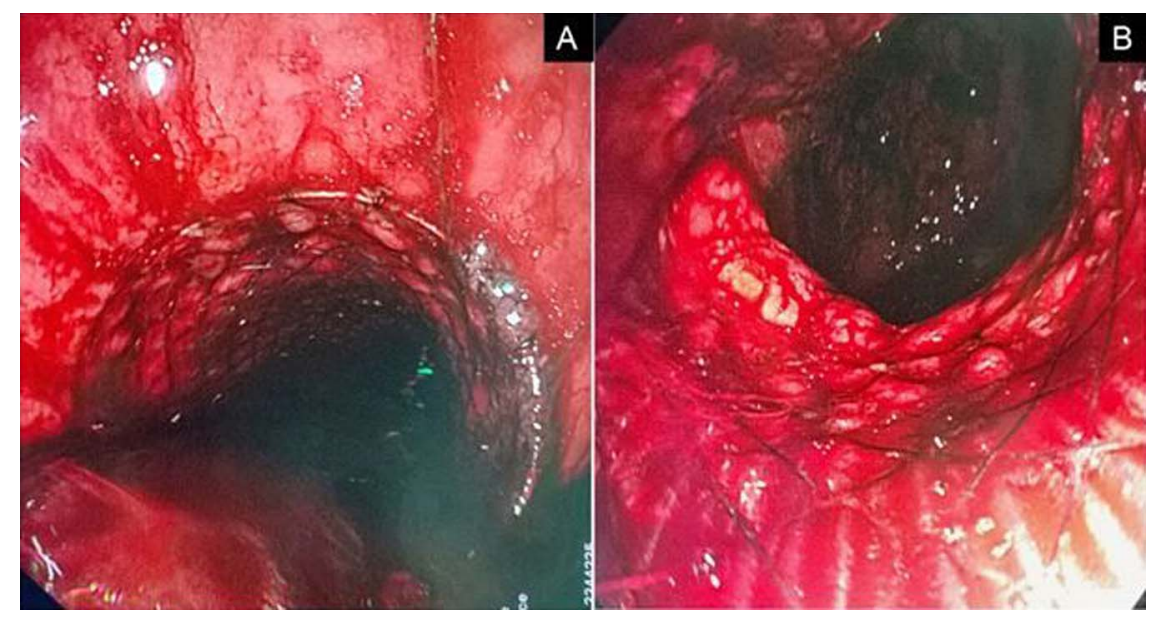

Figure 3 (A and B): Endoscopic views of a successfully deployed self-expandable metal stent for AVB. 
The studies in support of SEMS have mainly used the specifically designed SX-ELLA Danis stent (ELLA-CS, Hradec Kralove, Czech Republic) a removable, fully covered, polyurethane membrane-covered self-expanding metal stent (SX-ELLA stent Danis, $135 \mathrm{~mm} \times 25 \mathrm{~mm}$ ELLA-CS, Hradec Kralove, Czech Republic). The Ella Danis stent can be deployed without radiological or endoscopic guidance. The stent has atraumatic edges and radiopaque markers at both ends and midpoint of the stent to easily assess its position by plain radiography. The stent can be removed endoscopically using a special extractor kit (PEX-ELLA or Extractor for SX-ELLA stent Danis) without causing soft tissue damage. ${ }^{18}$

\section{EVIDENCE FOR SEMS IN AVB}

The initial pilot study by Hubmann et $a l^{19}$ was published in 2006, assessing SEMS as an alternative to BT in 20-patients (18 men, two women; mean age 52 years, Childs $\mathrm{B} / \mathrm{C}$ ) with refractory variceal bleeding despite pharmacological and endoscopic therapy. Three different types of stents were used; two (n-2/20) patients received standard oesophageal Choo stents $^{\mathrm{TM}}$ (diameter $18 \mathrm{~mm}$, length $140 \mathrm{~mm}$; NES-18-080-070, M.I.Tech, Korea), three $(n=3 / 20)$ a ELLA-Boubela-Danis stent (diameter $20 \mathrm{~mm}$, length 95 mm; ELLA-CS, Hardec Kralove, Czech Republic) and $15 \quad(\mathrm{n}=15 / 20)$ the specifically designed ELLA-Danis stent (diameter $25 \mathrm{~mm}$, length $135 \mathrm{~mm}$ ) that has a special introducer for placement without radiological or even endoscopic control. In all patients, upper endoscopy and chest X-ray were performed within $12 \mathrm{~h}$ to confirm correct stent position. In 19 $(n=19 / 20)$ patients, primary haemostasis (with no later rebleeding episodes), but in that one $(n=1 / 20)$ case, ongoing bleeding was attributable to GVB that resulted in the need for total gastrectomy and open azygoportal disconnection to control ongoing bleeding. Stent migration was observed in five $(n=5 / 20)$ cases, but only two $(n=2 / 15)$ patients with an ELLA-Danis stent. Reflective of the severity of bleed and associated liver decompensation with multiple organ dysfunction, in the absence of continued bleeding episodes, two $(n=2 / 20)$ patients died of multiple organ failure, at day 3 and day 5 day post-SEMS insertion, respectively. Four $(n=4 / 18)$ patients required scheduled VBL, however, the remaining $14(14 / 20)$ patients were bridged to more definitive treatment patients including TIPS $(n=5 / 18)$, laparoscopic azygoportal disconnection $(n=5 / 18)$, radiologically guided coiling $(n=1 / 18)$ and, ultimately, liver transplantation $(n=3 / 18) .{ }^{18}$ In 2008, Zehetner $e t a l^{20}$ reported their findings on 39 $(n=39)$ cases of SEMS insertion for refractory oesophageal AVB unresponsive to conventional methods. Thirty-four $(n=34 / 39)$ of these patients received a SX-ELLA Danis stent (deployed without fluoroscopy) leading to primary bleeding arrest in all $(n=34 / 39)$. No bleeding recurrence or stent-related complications occurred during or after stent implantation, nine $(n=9 / 39)$ patients died of hepatic failure within 30 days postprocedure. The median duration of stent implantation was 5 days (range 1-14 days) with all stents removed by endoscopy using the accompanying extractor device.

We have previously published our transplant centre experience of 10 cases of refractory variceal haemorrhage treated with a SX-ELLa Danis SEMS. ${ }^{21}$ A SEMS was successfully implanted in nine $(n=9 / 10)$ patients, with only one $(n=1 / 10)$ insertion failure due to inadequate delivery balloon inflation. Primary haemostasis was achieved with SEMS insertion in six $(n=6 / 9)$ patients, with continued bleeding reported in three $(n=3 / 10)$ cases, of which two were due to gastric AVB. Six $(n=6 / 10)$ patients survived the acute bleeding episode and had stents removed endoscopically at a median of 9 days after insertion. Overall survival at 42 days was $50 \%$. Only in one $(n=1 / 10)$ case was the process of SEMS insertion complicated (by a minor oesophageal ulcer) related to stent placement in what was otherwise a straightforward, quick and safe procedure with effective control of bleeding without the necessity for fluoroscopic control. This study also indicated that SX-Ella DANIS SEMS insertion offers an alternative to other methods of salvage such as BT and TIPS. Whether SEMS insertion is a substitute for primary EVL, for oesophageal, $\mathrm{AVB}$, or $\mathrm{BT}$, is the principle question of a current prospective randomised controlled trial from the same authors, with the results expected in 2014.

Dechene $e t a l,{ }^{18}$ published their experience of using SEMS for refractory AVB (despite standard pharmacological therapy) in eight $(n=8)$ cirrhotic patients with stenting resulted in immediate haemostasis and no reported rebleeding episodes in all cases. Three $(n=3 / 5)$ patients experienced recurrence of variceal bleeding within 9 days of stent removal. One $(n=1 / 8)$ patient with a high risk of rebleeding was bridged to TIPS; though post-TIPS rebleeding required TIPS dilatation. A further $(n=1 / 8)$ patient was bridged to orthotopic liver transplantation. Furthermore, SEMS were removed without complication after a median of 11 days. Mishin et $a l,{ }^{22}$ reported the case of a 49 -year-old man presenting with AVB on a background of (Childs-C) viral-induced cirrhosis. Primary haemostasis was initially achieved by VBL, but had a late massive rebleed from banding ulceration (on day 8). Placement of a SX-ELLA Danis stent led to complete haemostasis, with its removal at day-8 postinsertion without rebleeding or other complication. This case serves to highlight the benefit of SEMS as rescue therapy for variceal rebleeding (table 1).

\section{BALLOON-OCCLUDED RETROGRADE TRANSVENOUS OBLITERATION}

In the small group of patients with AVB advanced decompensated cirrhosis poorly amenable to TIPS 
Table 1 Evidence of SEMS in AVB.

\begin{tabular}{|c|c|c|c|c|c|c|c|c|}
\hline & Year & $\mathrm{n}=$ patients & $\begin{array}{l}\text { SEMS } \\
\text { successfully } \\
\text { deployed (\%) }\end{array}$ & $\begin{array}{l}\text { Immediate } \\
\text { haemostasis (\%) }\end{array}$ & $\begin{array}{l}\text { Rebleeding } \\
(\%)\end{array}$ & $\begin{array}{l}\text { SEMS } \\
\text { migration } \\
(\%)\end{array}$ & $\begin{array}{l}\text { Median (range) } \\
\text { days to stent } \\
\text { removal }\end{array}$ & $\begin{array}{l}\text { Mortality } \\
\text { follow-up } \\
\text { period }\end{array}$ \\
\hline $\begin{array}{l}\text { Hubmann } \\
\text { et al }\end{array}$ & 2006 & 15 & 100 & 100 & 0 & 13 & $5(1-14)$ & $20 \% 60$ days \\
\hline $\begin{array}{l}\text { Zehetner } \\
\text { et al }\end{array}$ & 2008 & 34 & 100 & 100 & 0 & 18 & $5^{*}(1-14)$ & $29 \% 60$ days \\
\hline $\begin{array}{l}\text { Wright } \\
\text { et al }\end{array}$ & 2010 & 10 & 90 & 70 & 14 & $N R$ & $9(6-14)$ & $50 \% 42$ days \\
\hline $\begin{array}{l}\text { Dechene } \\
\text { et al }\end{array}$ & 2012 & 8 & 100 & 100 & 38 & 0 & $11(7-14)$ & $75 \% 60$ \\
\hline $\begin{array}{l}\text { Holster } \\
\text { et al }\end{array}$ & 2013 & 5 & 100 & 100 & 20 & 20 & $11(6-214)$ & $40 \% 180$ days \\
\hline $\begin{array}{l}\text { Zakaria } \\
\text { et al }\end{array}$ & 2013 & 16 & 94 & 88 & 0 & 38 & NR (2-4) & $25 \% N R$ \\
\hline
\end{tabular}

*Represents mean (not median).

NR, not reported; SEMS, self-expandable metallic stents.

(contraindicated, technically/clinically challenging), and/or where other interventions have failed, balloon-occluded retrograde transvenous obliteration (BRTO) is a consideration. It is also a therapeutic option for ectopic varices. ${ }^{23}$ BRTO is available in only a very few specialist liver centres with good interventional radiology as essentially involves the difficult process of achieving transvenous access to the portosystemic circulation by a gastrorenal shunt commonly via venous puncture of the left renal vein through a transjugular or transfemoral approach. Moreover, sclerotherapy (eg, Ethanolamine oleate and sodium tetradecyl sulfate (STS) foam) is an important adjunct to mechanical balloon-occlusion to improve variceal obliteration. In a case series of 22 decompensated cirrhotics with AVB, BRTO achieved successful variceal obliteration in 91\%, with complications occurring in only $14 \%$ patients and no reported cases of recurrent variceal bleeding (mean clinical follow-up period of 130 days (range $1-510) .^{24}$

\section{FUTURE THERAPIES}

\section{Non-endoscopic}

Novel non-endoscopic approaches are also likely to add to therapeutic options. The most likely of these is Tranexamic acid, a plasmin inhibitor that maintains clot stability by limiting fibrinolysis, is currently being trialled in the Haemorrhage ALleviation with Tranexamic acid-InTestinal system (HALT-IT) study, a large, international, randomised, double-blind, placebo-controlled trial, directly evaluating its role in acute upper GI bleeding. However, a degree of caution is necessary, as previous interventions, such as Factor-VIIa, despite early promise failed in phase 4 studies to show a significant impact on AVB (failure to control acute bleeding, prevent 5 -day rebleeding and/ or death, and 42-day mortality) compared with placebo. ${ }^{25}$

\section{Endoscopic therapies}

There are little new endoscopic therapeutic approaches which show promise, but control of variceal bleeding with endoscopically applied haemostatic powder (Hemospray) looks interesting. This agent is an inorganic haemostatic powder that becomes cohesive and adhesive to form a stable mechanical barrier over the bleeding site; it is also reported to increase local clotting factors and activate the intrinsic clotting cascade. However, supportive data is currently limited to only a few case series predominantly in nonvariceal bleeding ${ }^{26}$ one case series, ${ }^{27}$ and isolated case reports in $\mathrm{GVB}^{28}{ }^{29}$; usually following failure of other endoscopic methods. Therefore, its use will need to stand up to more critical review with following more comprehensive randomised clinical trials.

Injection of Thrombin has been around for some time, but data had been limited. Recently however, a large prospective study suggests that Thrombin would be a good option for units where glue-injection is not already an option. ${ }^{30}$

\section{CONCLUSIONS}

In the management of AVB, SEMS has been rarely used outside of a few selected liver units, despite published non-randomised trial data suggesting improved outcomes versus standard medical therapy and OBL with ongoing/rebleeding variceal episodes. We therefore propose that SEMS should be the preferred intervention for refractory OVB after failed VBL or Sengstaken-Blakemoore tube (SBT) (figure 4). Moreover, randomised control trials are underway to establish whether this novel modality would be of benefit in the primary management in preference to EVL in current treatment algorithms. Although the relatively high unit cost $(£ 2000)$ per SEMS may initially be considered a limiting factor for its wider use, this should be offset against the 


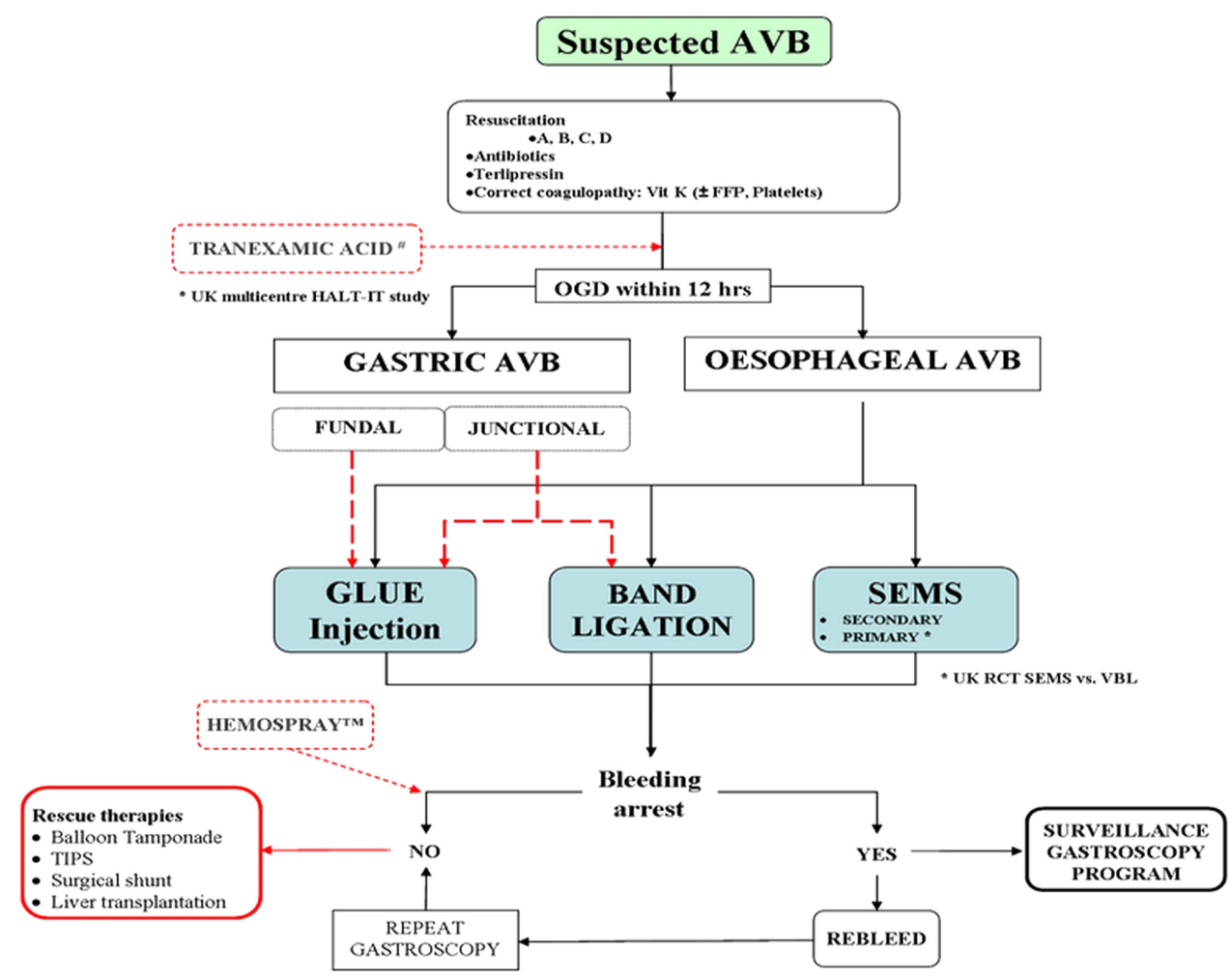

Figure 4 Proposed new acute variceal bleeding (AVB) management algorithm. All patients with suspected variceal bleed should be aggressively resuscitated, including correction of intravascular volume, coagulopathy, prophylactic antimicrobials, prokinetic (1 h pre-endoscopy to encourage lumen clot expulsion and aid visualisation), protein pump inhibitor, Terlipressin, and undergo therapeutic endoscopy within $12 \mathrm{~h}$ from presentation once stabilised (preferably for $2 \mathrm{~h}$ ). If patient remains unstable and/or high risk or expected prolonged procedure, endoscopy should be performed in theatre/ITU in an intubated patient with anaesthetic support, and a skilled endoscopist to attempt band ligation (current standard). A validated alternative is glue injection therapy (especially if a restricted luminal size (eg, paediatric cases) and/or multiple pre-existing bands/banding ulcers proves technically challenging; with glue injection therapy effective in cases of refractory oesophageal variceal bleeding despite prior recent intervention. Tranexamic acid, a plasmin inhibitor that maintains clot stability by limiting fibrinolysis, is currently under review in a large multinational study and, as such, can only be advocated as part of the AVB management algorithm outside of trial centres. Balloon tamponade (BT), preferably in experienced hands and placed endoscopy, remains a useful strategy if primary arrest cannot otherwise be achieved, and may allow the patient to be bridged to more definitive therapy (eg, further endoscopic therapy transjugular intrahepatic portosystemic shunt (TIPS) and/or transplantation). In oesophageal AVB, placing a 'self expanding metallic stent' has proven beneficial in cases of recurrent and/or failure of primary bleeding, and recently is under evaluation in randomised clinical trials (RCT) as first-line therapy, though currently cannot be advised outside of trial centres unless in experienced hands. For gastric AVB, glue-injection therapy is the current best endoscopic practice in units with experience; though there is some evidence that fundal gastric varices can be successfully treated with band ligation. AVB from gastric varices should be treated with histoacryl glue injection, and repeat injecting therapy will help to completely eradicate gastric varices. Refractory life-threatening variceal bleeding, or rebleeding, remains a challenging problem with complete haemostasis usually not obtained despite multiple therapeutic modalities. Currently, intubation, ITU admission (with multiorgan support), and BT, with a view to transfer for rescue therapy such as TIPS/shunt is advised. There is some emerging evidence for the use of hemospray to control refractory AVB and allow for stabilisation until bridged to rescue therapy. Hemospray is currently being assessed in a multinational RCT and shows promise and, as such, cannot be advised outside of trial centres. If able to maintain haemostasis through admission, then once patient is stable with improved liver function (on treatment) they should be booked for tailored scheduled endoscopic banding programme.

significant cost savings due to less rebleeding episodes and sequelae.

Additionally, there is good and growing evidence for endoscopic variceal obliteration using N-butyl-2-cyanoacrylate as a first-line endoscopic therapy for AVB, especially for GV bleeds where treatment options remain limited.

Contributors All authors contributed equally to the concept, data collection, and manuscript development.

Competing interests None.
Provenance and peer review Not commissioned; externally peer reviewed.

Open Access This is an Open Access article distributed in accordance with the Creative Commons Attribution Non Commercial (CC BY-NC 4.0) license, which permits others to distribute, remix, adapt, build upon this work non-commercially, and license their derivative works on different terms, provided the original work is properly cited and the use is noncommercial. See: http://creativecommons.org/licenses/by-nc/4.0/

\section{REFERENCES}

1 Williams SGJ, Westaby D. Management of variceal bleeding. BMJ 1994;308:1213-17.3 
2 Sharara AI, Rockey DC. Gastroesophageal variceal hemorrhage. N Engl J Med 2001;345:669-81.

3 Bernard B, Grange JD, Khac EN, et al. Antibiotic prophylaxis for the prevention of bacterial infections in cirrhotic patients with gastrointestinal bleeding: a meta-analysis. Hepatology 1999;29:1655-61.

4 American Society of Gastrointestinal Endoscopy (ASGE). Technology status evaluation report-Sclerosing agents for use in GI endoscopy. Gastrointest Endosc 2007;66:213-18.

5 Jalan R, Hayes PC. UK guidelines on the management of variceal haemorrhage in cirrhotic patients. BSG Society in Gastroenterology. Gut 2000;46(Suppl 3-4):III1-15.

6 Sarin SK, Govil A, Jain AK, et al. Prospective randomized trial of endoscopic sclerotherapy versus variceal band ligation for esophageal varices: influence on gastropathy, gastric varices and variceal recurrence. J Hepatol 1997;26:826-32.

7 Cipolletta L, Zambelli A, Bianco MA, et al. Acrylate glue injection for acutely bleeding oesophageal varices: a prospective cohort study. Dig Liver Dis 2009;41:729-34.

8 Helmy A, Hayes PC. Current endoscopic therapeutic options in the management of variceal bleeding. Aliment Pharmacol Ther, Jan 2002. doi:10.1046/j.1365-2036.2001.0095

9 García-Pagán JC, Caca K, Bureau C, et al. For the early TIPS (Transjugular Intrahepatic Portosystemic Shunt) cooperative study group. N Engl J Med 2010;362:2370-9.

10 Krystallis C, Masterton GS, Hayes PC, et al. Update of endoscopy in liver disease: more than just treating varices. World J Gastroenterol 2012;18:401-11.

11 Belletrutti PJ, Romagnuolo J, Hilsden RJ, et al. Endoscopic management of gastric varices: efficacy and outcomes of gluing with N-butyl-2-cyanoacrylate in a North American patient population. Gastroenterol 2008;22:931-6.

12 Al-Ali J, Pawlowska M, Coss A, et al. Endoscopic management of gastric variceal bleeding with cyanoacrylate glue injection: safety and efficacy in a Canadian population. Can J Gastroenterol 2010;24:593-6.

13 Rajoriya N, Forrest EH, Gray J, et al. Department of Gastroenterology, Glasgow Royal Infirmary, 84 Castle Street, Glasgow, G4OSF, UK. QJM 2011;104:41-7.

14 Wright G, Matull WR, Zambreanu L, et al. Recurrent bacteremia due to retained embolized glue following variceal obliteration. Endoscopy 2009;41(Suppl 2):E56-7.

15 Liao SC, Ko CW, Yeh HZ, et al. Successful treatment of persistent bacteremia after endoscopic injection of $\mathrm{N}$-butyl-2-cyanoacrylate for gastric varices bleeding. Endoscopy 2007;39(Suppl 1):E176-7. http://www.thieme-connect.de/ journals/toc/endoscopy/29237

16 Binmoeller KF, Weilert F, Shah JN, et al. Transesophageal treatment of gastric fundal varices with combined coiling and cyanoacrylate glue injection. Gastrointest Endosc 2011;74:1019-25.
17 Romero-Gomez M, Brullet-Benedi E, Romero-Vazquez J, et al. EUS-guided coil versus cyanoacrylate therapy for the treatment of gastric varices: a multicenter study. Gastrointest Endosc 2013;78:711-21.

18 Dechene A, El Fouly AH, Bechmann LP, et al. Acute management of refractory variceal bleeding in liver cirrhosis by self-expanding metal stents. Digestion 2012;85:185-91.

19 Hubmann R, Bodlaj M, Czompo L, et al. The use of self-expanding metal stents to treat acute esophageal variceal bleeding. Endoscopy 2006;38:896-901.

20 Zehetner JJ, Shamiyeh A, Wayand W, et al. Results of a new method to stop acute bleeding from oesophageal varices: implantation of self-expanding stent. Surg Endosc Other Interv Tech 2008;22:2149-52.

21 Wright G, Lewis H, Hogan B, et al. Our experience of nine patients treated with a self-expanding metallic esophageal Stent (SEMS) for the arrest of acute variceal bleeding, its complications and/or the complications of intervention. Gastrointest Endosc 2010;71:71-8.

22 Mishin I, Ghidirim G, Dolghii A, et al. Implantation of selfexpanding metal stent in the treatment of severe bleeding from oesophageal ulcer after endoscopic band ligation. Dis Oesophagus 2010;23:E35-8.

23 Borghei P, Kim S. Balloon-occluded retrograde transvenous obliteration (BRTO) of gastric varices in 18 patients with relative contraindications for TIPS or failed TIPS in single US medical center. J Vasc Interv Radiol 2013;24:S116.

24 Sabri SS, Swee W, Turba UC, et al. Bleeding gastric varices obliteration with balloon-occluded retrograde transvenous obliteration using sodium tetradecyl sulfate foam. J Vasc Interv Radiol 2011;22:309-16. quiz 316.

25 Bosch J, Berzigotti A, Garcia-Pagan JC, et al. The management of portal hypertension: rational basis, available treatments and future options. J Hepat 2008;48(Suppl 1):S68-92.

26 Sung JJ, Luo D, Wu JC, et al. Early clinical experience of the safety and effectiveness of Hemospray in achieving hemostasis in patients with acute peptic ulcer bleeding. Endoscopy 2011;43:291-5.

27 Ibrahim M, El-Mikkawy A, Mostafa I, et al. Endoscopic treatment of acute variceal hemorrhage by using hemostatic powder TC-325: a prospective pilot study. Gastrointest Endosc 2013;78:769-73.

28 Holster IL, Poley JW, Kuipers EJ, et al. Controlling gastric variceal bleeding with endoscopically applied hemostatic powder (Hemospray ${ }^{\mathrm{TM}}$ ). J Hepatol 2012;57:1397-8.

29 Stanley AJ, Smith LA, Morris AJ. Use of hemostatic powder (Hemospray) in the management of refractory gastric variceal hemorrhage. Endoscopy 2013;45(Suppl 2 UCTN):E86-7.

30 McAvoy NC, Plevris JN, Hayes PC. Human thrombin for the treatment of gastric and ectopic varices. World J Gastroenterol 2012;18:5912-17. 